\title{
سبل تتشيط التجديف الرياضي بمحافظة أسوان
}

الباحث / مصطفي أحمد عبدالثافي

\section{ملخص البحث}

تعد السياحة الرياضية اهم انماط السياحة المصرية سواء الداخلية او الخارجية وهي تساهم في رفع مستوى الاقتصاد القومي وتضم محافظه اسوان عدد كبير من مقومات جذب السياحة الطبيعية والاثرية والصحراوية بما يجعلها تتمتع بميزه تتافسيه في السياحة بوجه عام وبالرغم من هذه المقومات الا انها لا تستغلها بشكل كافي يتتاسب بهاب مع الموارد المتاحة التي تساعد في نمو تتشيط التجديف الرياضي ومقوماته وانماطه المناسبة بمحافظه اسوان وتوصل الى اهم مقومات التجديف الرياضي وانماطه السياحيه وسبل تتشيط بمحافظه اسوان والتي اسفرت عن وجوده مناخ و شواطئ اسوان كوسيلة جذب للسياحة الرياضية طوال العام ورغم ذلك لا يتم استضافه الفرق الرياضية المختلفة بشكل كافي مع قله تتظيم البطولات الرياضية الثاطئية المحلية والدولية وكذلك

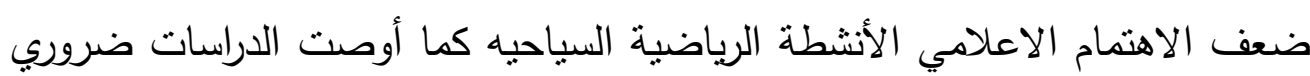
تشكيل هيكل نسويقي للأنشطة التجديف الرياضي بكل منشأه سياحيه لتسويق ذلك

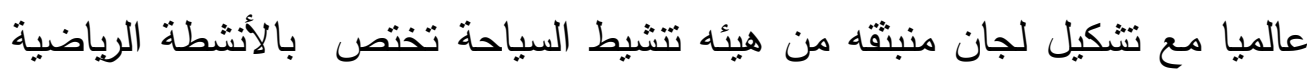
السياحية

\section{مقدمة البحث}

تعتبر محافظه اسوان من اهم محافظات مصر من حيث المقومات السياحية والمتمثلة

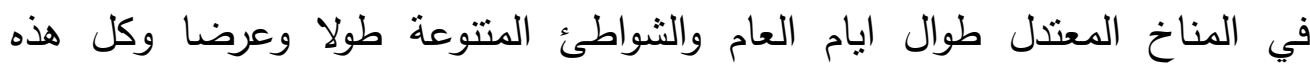
المقومات لا توجد متجمعة في كثير من البلدان العالم وهي بذلك تمثل مصدر هام للسياحة الرياضية نظرا لما تتمتع به من مناخ ومقاومات سياحيه منتوعه و تعد السياحة الرياضية اهم انماط السياحة التي تساهم بشكل فعال في تنشيط حركه السياحة 
المصرية سواء الداخلية او الخارجية وبالتالي رفع مستوى الاقتصاد القومي وفى الوقت الحاضر لم تعد السياحة تقتصر على زياره الاثار القديمة التي خلفها الاجداد لكن بدأ هناك اتجاه عالمي جديد لربط السياحة بالرياضة بما يحقق خدمة كلاً منهما للأخر و تعتبر السياحة في مصر قاطره التتمية الاقتصادية، فالسياحة في مصر تعني ما يقارب

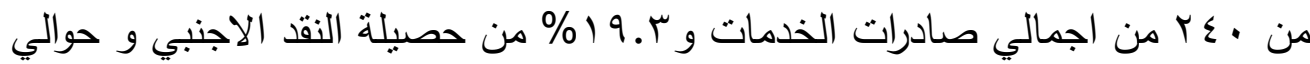
V V V من اجمالي النتائج المحلي بصوره مباشره، كما تعتبر اهم قطاعات الدولة توفيراً لفرص العمل حيث يصل نسبه الذين يعملون بها سواء بصوره مباشره او غير مباشره حوالي 7. Y ا \%من اجمالي حجم العمالة في الدولة. وتمنت السياحة مجموعه من العلاقات والخدمات المرتبطة بعمليه تغيير المكان تغيير وقتيا وتلقائيا وليس لأسباب تجاريه او حرفيه فقط في العلاقات السياحية مجموعتان منفصلتان تسمى الاولى مجموعه العلاقات المادية حيث ينتفع السائح بالعديد من الخدمات مقابل دفع اجر مادي وتسمى الثانية مجموعه العلاقات الغير ماديه (الانسانية او المعنوية)و التي تتتج من اتصال السائح وتعاملهم مع الثعوب الدولة المختلفة والتي هي يزودها بمقاومات النقافية والسلوكية والاجتماعية والبيئية

\section{المشكلة}

تضم محافظه اسوان عدد كبير من مقومات الجذب السياحي سواء الطبيعية او الاثرية او الصحراوية ما يجعلها تتمتع بميزه تتافسيه في السياحة بوجه عام و هذه المقومات تأهلها ايضا للتنافس في التجديف الرياضي بوجه خاص وذللك بسبب ما تتمتع به محافظه اسوان من شواطئ جذابه و مياه صافيه جميله نظرا لوقوع نهر النيل في منطقه معتلالة وبالرغم من هذه المقومات الطبيعية والمميزات السياحية الموجودة بأسوان الا انها لا تستغل بشكل كافي او يتتاسب او يتوافق مع الموارد المتاحة التي نساعد في

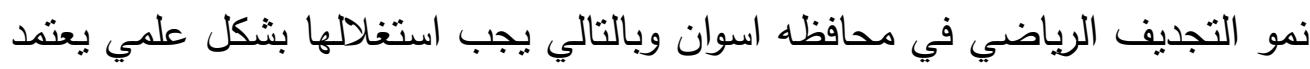

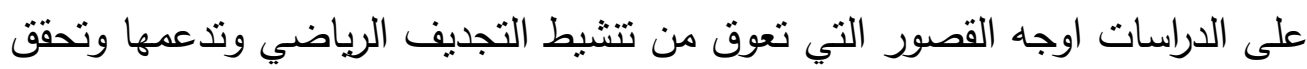


تأثثرات ايجابيه وهذا الامر يستند توضيح سبل تتشيط التجديف الرياضي بمحافظه اسوان والاستفادة من الموارد الطبيعية كأحد اهم مرتكزات تتشيط السياحة بوجه عام بمحافظه اسوان واوضح البحث ان قله الاستثمارات المحلية والعربية والاجنبية بالمنطقة السياحية التي تستقبل البطولات الرياضية اهم التحديات التي تواجه هذا النوع من الرياضة ويؤكد ذلك قله انثاء النوادي والفنادق السياحية لهذا الغرض والمزاحمة بين القطاعين العام والخاص ولا توجد شركه حقيقيه بينهما تدعم منتج التجديف الرياضي وتتمل التحديات نقص البرامج التدريبية للعاملين بالقطاع السياحي وقله العمالة المدربة والمؤهلات في بعض المنشآت التي تخدم النشاط الرياضي بمختلف الاماكن السياحية والافتقار الى وجود سياسه تسويق سياسه تصوير قادره على توجيه منتج التجديف الرياضي بشكل يناسب مع رغبات التسويق المستهدف

\section{مصطلحات علمية}

1. التجديف: هو عملية دفع القارب بالمجداف ، حيث يقوم الثخص بمسك

مجاديف القارب وتحريكها للأكام و للخلف لتحريك القارب.

$$
\text { r. الدفة: هي التي يتم بها توجيه القارب. }
$$

r. المجداف: بصنع المجداف من موارد من الخشب المنين أو المطاط وطوله · ب اسم وعرض الكفة7 (سم •

\section{أنواع القوارب}

هناك قوارب بمجداف لكل لاعب وقوارب بمجدافين لكل لاعب

$$
\begin{aligned}
& \text { 1. الفردية } \\
& \text { r. الزوجية } \\
& \text { r. ب. الرباعية } \\
& \text { ع. ذات الثمان مقاعد }
\end{aligned}
$$




\section{اهمباd البحث:}

تتمثل اهميه البحث في دراسة مشكله التجديف الرياضي بمنطقه اسوان والعمل على دعم هذا المجال والذي يسهم بشكل كبير في تتميه صناعه السياحة في مصر بوجه عام والتجديف الرياضي بشكل خاص مما يعود بالنفع على الاخل القومي و تأثيرها الايجابي على الاقتصاد الوطني من خلال خلق استثمارات جديده وتوفير فرص عمل

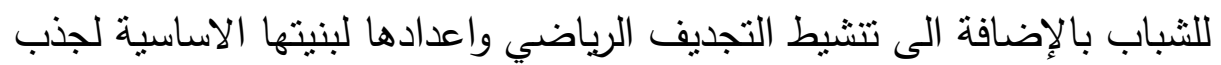
السياحة والفرق العالمية لإقامة المعسكرات التّريبية في محافظه اسوان كما أكد البحث على ضرورة الترويح الفعال للتجديف الرياضي من خلال الجهات المسؤولة عن تتظيم المسابقات الرياضية وتحفيز منظمي الرحلات السياحية لنتظيم برامج لمحافظه اسوان لتستقبل البطولات الرياضية المتتوعة وفقا لتقديرات منظمه السياحة العالمية فان شركات السياحة العالمية تواجه الى نحو هب \% من حجم السياحة تجاه المقاصد السياحية التي تستقبل مختلفة العاب الرياضية 


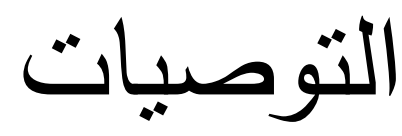

في ضوء اهداف و تساؤلات البحث والنتائج و الاستخلاصات يوصي الباحث بمايلي

1. تنظيم بطو لات عالميه بمحافظه اسوان بصوره منتظمة وفقا للنظم السياحة

العالمية

r. تشكيل هيكل تسويقي للنشطة الرياضية او السياحة بكل منشأه سياحيه

لتسويق ذلك عالميا

r. تشكيل لجان منبثقة من هيئه تنشيط السياحة تختص الانشطة الرياضية

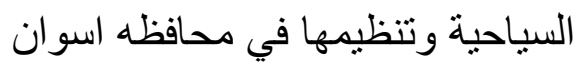

ع. اقامه بطو لات شاطئيه دوريه في الالعاب المختلفة بما يتماثى مع الطبيعة

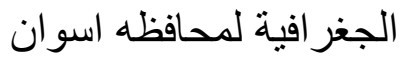

0. تقديم الخدمات للسائحين وفقاً لطبيعة عادات وتقاليد سائحي كل دوله

7 7. توفير العمالة السياحية المدربة بثكل يليق بما تقدمه المنشأة من خدمات

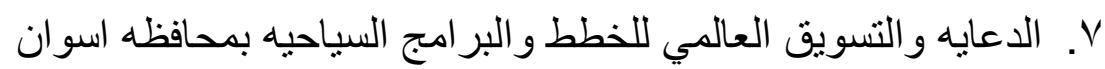
لاستقطاب اكبر عدد ممكن من السائحين

^. الاهتمام بتقديم بر امج ترويحيه لخدمات السائحين من كبار السن

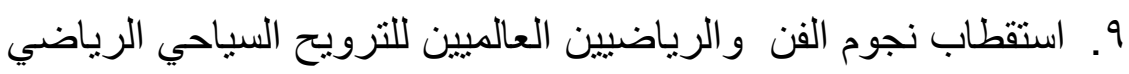
بمحافظه اسوان

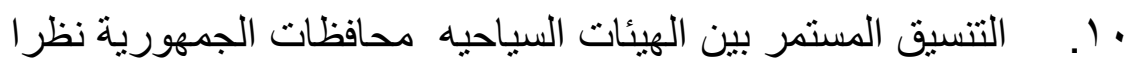
لتنوع الخدمات السياحيه

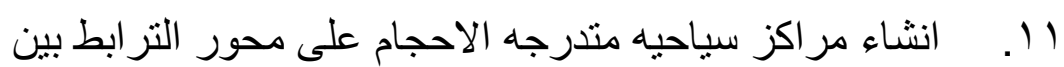

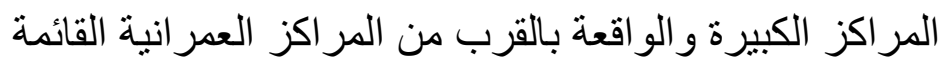




\section{المراجع}

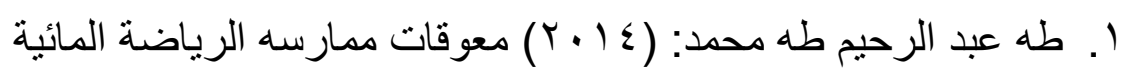
الترويحية اله

r. فاطمه هانم محمد علي: (999 (199) مكانة الرياضة من من السياحة بجمهوريه

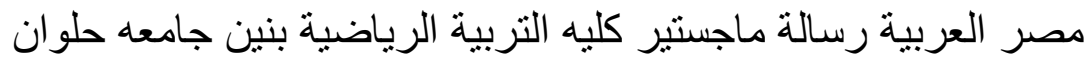

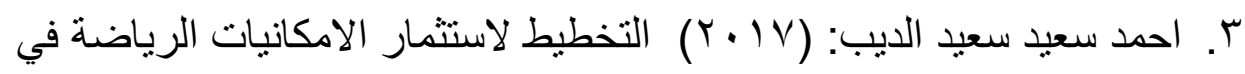

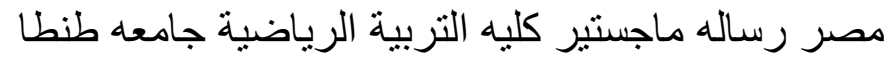

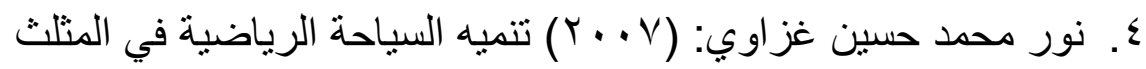
الذهبي في الاردن رساله ماجستير كليه التربية الرياضية جامعه اليرموك 